\title{
Chew-through behavior in rats
}

W. E. WILSONCROFT

SAN FERNANDO VALLEY STATE

This study explores the stimulus conditions under which rats will elect to chew through cardboard barriers to gain access to an empty chamber. With a thin barrier that allowed visual exploration of the second chamber $70 \%$ of the Ss elected to chew through the barrier; when $S$ s were first allowed free access to both chambers, followed by barriers of increasing thickness, only $15 \%$ of the Ss chose to chew through the barriers. The concept of stimulus "pacers" is utilized to interpret the data.

Although chewing and gnawing are among the most ubiquitous of rodent behaviors, little research has focused directly on these activities (Bartnett, 1963; Bindra, 1959). Current motivational theory (Berlyne, 1960; Dember \& Earl, 1957) points to the efficacy of exploratory and manipulatory behaviors as reinforcers. For example, Earl (1950) noted that mice would continue to dig sand to gain access to a food chamber even on extinction trials when no food was available. Shupe (1950) has extended the results on sand-digging without primary rewards. Under certain stimulus conditions his Ss would dig their way through over 30 pounds of sand in a single day's testing merely to enter and empty chamber! Shupe (1966) concluded that sand-digging in rats is contingent upon their being "paced"-i.e., presented with work loads that are initially low and then increased by incremental amounts.

The present study explores the chewing behavior of rats. Primary interest is in the stimulus conditions under which rats will elect to chew through cardboard barriers to gain access to an empty chamber.

Method

All Ss $(N=16)$ were housed individually in home cages with ad lib food and water. Chewing behavior was tested on $2 \mathrm{~h}$ test trials for 10 consecutive days. Ss were not handled, but rather moved directly into the test chambers from their home cages to begin testing, and were coaxed back into their cages after testing. The test chambers consisted of two compartments measuring $3 \times 1-1 / 2$ ft each; the chambers were separated by a central dividing partition with a 4 in. square connecting doorway. No food or water was ever present in the testing chambers. The connecting doorway was blocked by varying thicknesses of cardboard as descrtbed below. The major dependent variables of concern were: (a) the number of Ss that would elect to chew through the cardboard barriers to gain access to the second chamber and (b) the number of grams of cardboard the Ss would chew through.

Ss were divided into four groups $(\mathrm{N}=4$ each) that were tested under the following conditions: (1) doorway completely blocked by a solid cardboard barrier on all trials; (2) doorway blocked on all trials by a thin cardboard barrier (1/4 in. thick) with a $1 / 4$ in. sq. opening cut in the bottom. This small opening allowed Ss to explore visually the second chamber and proved a significant parameter in the study; (3) doorway initially blocked by $a$ thin (1/4 in. thick) barrier, with a small (1/4 in. sq.) vlewing hole, followed by increasingly thick cardboard barriers $(1 / 4,1 / 2,3 / 4,1$, and $1-1 / 4$ in. thicknesses for two testing days); and (4) doorway initially open allowing free access to both compartments, followed by barriers of increasing thickness over testing days.

Results

Table 1 shows the number of Ss in each group that chewed upon the barriers and the number of Ss that successfully chewed through the barrier and gained access to the second chamber. Table 2 shows the number of grams of cardboard chewed by Ss in each of the groups ( $.4 \mathrm{~g}=1 \mathrm{sq}$. in. of cardboard).

Discussion

As can be seen in Table 1, when rats (Group 1) were presented with a solid barrier of cardboard they did not respond by chew through behavior or even biting into the barrier. None of these $\mathrm{Ss}$ engaged in any chewing activity. However, when $E$ cut a small (1/4 sq. in.) viewing hole in the cardlooard barrter such that the Ss could visually explore the second compartment, $70 \%$ of the Ss (Group 2) engaged in chew through behavior. When the thickness of the barrier was incrementally increased (Group 3)-or when Ss were initially given free access to both compartments and

Table 1

Number of Se in each group that chewed upon the barrier and number of Ss that were successful in (chewing through) the barrier to gain access to the second chamber.

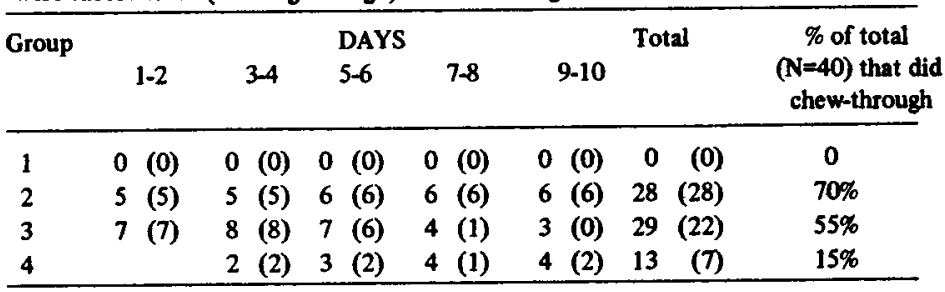


Table 2

Number of grams of cardboard chewed $(.4 \mathrm{gm}=1 \mathrm{sq}$ in. sufficient to chew through a barrier $1 / 4 \mathrm{in}$. thick)

\begin{tabular}{ccccccc}
\hline Group & $1-2$ & $3-4$ & $5-6$ & $7-8$ & $9-10$ & Total \\
\hline 1 & 0 & 0 & 0 & 0 & 0 & 0 \\
2 & 5.4 & 5.3 & 12.9 & 5.3 & 5.9 & 34.8 \\
3 & 8.1 & 14.4 & 15.6 & 6.8 & 9.1 & 54.0 \\
4 & & 3.3 & 4.4 & 2.8 & 7.7 & 18.2 \\
\hline
\end{tabular}

then barriers were inserted and gradually increased in thickness (Group 4)-the Ss showed a decreasing interest in chewing through the barriers. Thus the particular "pacers" employed in this study failed to induce chew through behaviors. Different pacing schedules might, however, better encourage the chew through type of behavior observed in Group 2.

It should also be noted that some Ss never did engage in the chew through activity. Even in Group 2, where about $70 \%$ of Ss engaged in chew through behaviors, some Ss persistently paid no attention to the carboard barriers. In contrast, other Ss repeatedly not only did chew through the barrier but also would return and tear down all the remaining cardboard, sometimes chewing down many grams of cardboard in excess of the amount needed to get through the doorway. Other materials have been tentatively tested for chew- ing behaviors. These included balsa wood and Styrofoam. The latter material, being the softest, produced the greatest effect, as most all the Ss readily engaged in chewing through this material.

Another factor that may be pertinent to the present study was that of social factlitation. Ss were run elght at a time during most of the testing. E placed all Ss in their separate test chambers and then left the room for the $2 \mathrm{~h}$ testing period. As soon as the door was closed it was not uncommon to hear a loud sound of tearing cardboard. This frantic activity was less common in the later stages of the testing sessions.

References

BARNETT, S. A. The rat: A study in behavior. Chicago: Aldine Publishing Company, 1963.

BERLYNE, D. E. Conflict, arousal, and curiosity. New York: McGrawHill, 1960.

BINDRA, D. Motivation: A systematic reinterpretation. New York: Ronald Press, 1959.

DEMBER, W. N., \& EARL, R. W. Analysis of exploratory, manipulatory, and curiosity behavior. Psychol. Rev., 1957, 64, 91-96.

EARL, R. W. The effects of varied motivation on the sand-digging behavior of the mouse. Unpublished Masters Thesis, Stanford University, 1950.

SHUPE, D. V. Sand digging in rats. Unpublished Masters Thesis, Claremont Graduate School, 1967.

Note

1. Paper presented at WPA, San Francisco, 1967. The author expresses his thanks to Mr. G. W. Watson for his assistance in this project. 